\title{
THE NEED FOR INNOVATION OF SECURITY EDUCATION FOR STRENGTHENING THE RESULTS OF TRADITIONAL TEACHING AT UNIVERSITIES
}

This article deals with security education and the possibilities of innovative methods application in this kind of education at universities. The continuous development of science and technology, as well as constantly changing social needs which are closely tied to the emergence of new security risks and threats, dynamically affect the entire system of education. Therefore, an urgent need for the implementation of these requirements arises. There is a need to address the number of key roles in the framework of security education in the spirit of innovation methods in order to improve teaching and, subsequently increase the efficiency of the process.

Keywords: Security education, universities, innovative methods, efficiency.

\section{Introduction}

The tasks of educational work, which are supposed to shape the personality of a student more effectively have significantly expanded and became more complicated at universities. Requirements for the educational process in college education continue to grow. The frequently changing social needs, but also the continuing development of science and technology which are closely tied to the emergence of new security risks and threats, dynamically affect the entire education system. In relation to this, the reaction to achievement of better results in the process of security education should be the creation of realistic assumptions to prepare professionals that are broadly educated, creativelythinking, and capable of rapid adaptability to new conditions.

The aim of education is to prepare a group of experts for the management of security institutions of different sizes and varying degrees of complexity. It is necessary to develop and clarify its own terminology of the relevant terms, used in the preparation of security experts - in education of security management specialists [1]. The objectives and tasks of the teaching process help create optimal conditions for the conscious and positive activity of welleducated and skilled security managers of different specializations [2].

Digital world is a natural part of the daily life of university students nowadays. New hardware and software school equipment, such as interactive whiteboards, voting machines, laptops and tablets, but also freely available educational software, raise questions about their effective use in the educational process. Classic and innovative educational methods and forms have a new dimension in the digital environment. However, new methods closely connected with the usage of digital technologies arise [3].

In addition to technical and scientific progress, or rather in close connection with it, there are also lifestyle changes, acceleration of development of young people, new knowledge about learning and a number of other factors that significantly affect pedagogical practices so far. The basic aim of college education is the formation of fully trained cognoscente who is capable of self-complementation of knowledge, and self-increasing of general-theoretical and professional level.

\section{The essence of security education at universities}

When facing the challenges of security, education and training of security services personnel and personnel at different levels of security and management as well as managing workers on which high demands for knowledge are placed, are important aspects. Within university education, improvement of the situation in given area can be achieved by increasing of security awareness of people coming out of school to practice, and by deepening of their knowledge and skills associated with security, by improving qualifications and skills of graduates and preparing them to

\footnotetext{
* 1Martina Vackova, ${ }^{1}$ Lucia Kovacova, ${ }^{1}$ Maria Kancirova, ${ }^{2}$ Peter Losonczi

${ }^{1}$ Institute of Humanitarian and Technological Science, University of Security Management in Kosice, Slovakia

${ }^{2}$ Institute of Civil Security, University of Security Management in Kosice, Slovakia

E-mail: martina.vackova@vsbm.sk
} 
deal with risk, emergency and crisis phenomena in various aspects of security (civil, economic, environmental, technical and technological, logistical etc.). We can therefore speak about security education, which contains the theoretical and practical knowledge about the protection of property and individuals with the possibility of versatile use in the European security environment. The essence of security education lies in the analytical work which is aimed at averting or minimizing security risks of different forms and causes to individuals and to society as a whole. Security education does not only concern the increasing of education and skills of security services workers, experts in the field of security and management personnel. It is appropriate to understand security education as an effective education system building security awareness and shaping attitudes to safety behaviour and actions in lifelong learning from preschool education to education of economically active citizens. However, we focus on security education and its innovation only in terms of universities for the purpose of this article [4].

The system of security education must be channelled in such a way that security personnel is allowed to obtain and acquire knowledge and understanding of methods by which they will be able to analyse the security environment and its factors in relation to various objects, identify and assess security risks and threats and predict their evolution, determine the procedures and management measures, security risks and threats, to plan and organize the risk management measures, security and crisis management in line with available resources and capacities to design and manage complex security systems [5].

\section{Streamlining the traditional teaching safety education in conditions of universities}

Deficiencies arising in security education prevent the effective investigation of professional and social aspects of security problems, by which the basic cognitive element for effective management of security systems is limited. The deficiencies arising in this education need to be addressed examined and removed. Therefore, the need to evaluate teaching in terms of pedagogical efficiency arises and we need to focus on innovation of this process. Security education at universities is in the direct teaching system realized by system of all elements of the teaching process.

With some simplification, it can be concluded that the objectives of this process are reflected in the content of teaching, which is implemented in the organizational forms, through methods using teaching aids and teaching techniques and in particular conditions its security. Each element of the teaching process represents internal possibilities of increasing efficiency of education [6]. All are interrelated and contingent. There is an objective connection between them, which impacts the overall results of the teaching processes. Therefore, the rate of quality and efficiency of this process is always dependent on the use of the opportunities of individual elements, as well as on achieving the most favourable relations between them [7].

Traditional teaching is mainly characterized by expositoryillustrative and reproductive methods primarily used on lectures, exercises, and seminars. Both methods ensure the acquisition of final knowledge and experience from implementation of known ways of actions.

These two cognitive teaching methods ensure the preparation of the young generation for reproduction but cannot teach creative activity. It is possible especially in troubleshooting teaching. Traditional cognitive methods cannot be criticized; they are still needed in modern teaching. Pedagogue should however innovate the forms of their implementation, for example through the utilization of computer technology in appropriate learning activities of students [8].

Possibilities of increasing of the efficiency of education are relatively broad, however it is important to choose the most suitable in the particular conditions. For selecting appropriate possibilities of increasing of the effectiveness of education, it is primarily necessary to assess the current status of education in those conditions, which provide the foundation for solving of research problems in this important area of pedagogy.

\section{Appropriate innovative methods in the process of security education at universities}

Even before the advent of digital technology, creative, innovative pedagogues promoted constructivist learning instead of instructionist learning of scientific subjects.

Instructionist learning is linear and systematic, the student is passive in such learning. Pedagogue demonstrates and explains, while student copies and integrates. The content of learning is seen as a closed system of knowledge and elements. Many pedagogues currently prefer this instruction. The reasons are different (lack of time, lack of quality textbooks and instructional materials, lack of creativity of the pedagogue etc.).

Constructivist theory of cognition and learning was developed by Swiss psychologist Jean Piaget. He starts from the premise that the student in active interaction with the environment gradually creates its internal system of knowledge. Learning process should take place in an inspiring educational environment that inspires students to research. Pedagogical constructivism requires that teaching should only deal with solutions of real life (specific and authentic) problems. It also requires creative thinking, work in groups, manipulation with objects, visual aids e.g. interactive computer programs. In constructivism, more than one current exists, but all of them present learning with comprehension. Understanding is created by student himself (by considering new information, comparing them with previous experience, knowledge and schemes). It is therefore a problem teaching. 
Constructivist approaches include the management method to investigate or method ERR (evocation - realization of meaning reflection). Extraordinary effective form of controlled examination is Workshops method, foundation of which is a group form of education with the principle of small steps, while respecting the principle of succession and performance, active student learning and immediate verification and own pace.

Method of creating bunches of problems also belongs to this group. It is based on identification of a suitable initial problem, which will be solved by students together with a pedagogue. Subsequently, after the resolution of the initial problem, students solve similar problems that do not differ significantly from the original. The method of solution of these problems is the same or very similar to the method of the solution of the original problem. After specific training, the aim is to draw students into a process of creation of the new problems that are becoming more and more distant from the original problem.

After certain training, the aim is to draw students into the process of creating new problems in such a way that they will gradually form problems that are more and more distant from the original one.

Project teaching is another form of mobilizing of teaching of science subjects that takes entirely new opportunities in the digital environment. Digital technologies such as computer, internet, digital camera, mobile phone, etc. are an excellent means when working on projects for students not only in collecting information, but also in data processing, real life situations modelling, in the calculations and also in the presentation of results.

The problems that students solve in project education are complex and their solution will require the knowledge of several sciences (traditional teaching subjects). Problems are solved by groups of students (cooperative teaching) mostly from selfinterest and solutions lead to concrete results, product, written reference, etc. Such complex problems are called projects.

Nowadays, the usage of digital technology (computers, internet, software, mobile phones, digital cameras, etc.) in teaching is for students a certain connection between a subject (subjects) and real life, in which these technologies are commonly used. Even at home environment, students are often informed about solutions to various projects in real-life for example by their parents, older siblings etc. It is common for employees of different companies that within their employment they work on solution of various kinds of projects and to some extent use the ICT solutions. At schools, pedagogues are involved in projects in order to obtain grants and purpose finances. Therefore mimicking this activity by students within a well prepared project teaching with usage of digital technologies can be considered as one of the most current methods of teaching.

In order for project method with the use of ICT to work well, the presumption for creative, educated, innovative and digitally literate pedagogue must be fulfilled.
Pedagogue forms his students by his direct and indirect activity, qualification, expertise, pedagogical mastery and also personal example. If we want to nurture young people info information-skilled and creative people with the ability to solve problems in real life independently, pedagogues must have their lessons prepared competently, creatively, interestingly and modernly.

The onset of digital technology came in two forms: instructionist and constructivist approach. Pedagogues often use Microsoft PowerPoint presentations or prepared Flipcharts with interactive whiteboard as a form of "taking notes" digitally instead of the classical blackboard and chalk. Often it is the only electronic support of "classical", instructionist teaching. New constructivist approach to teaching with digital support for students is very interesting, motivating, and energizing, but from the perspective of pedagogue also very challenging for preparation (e.g. professionally). The biggest reserves can be seen in the lack of quality teachers and accessible electronic materials for constructionist teaching.

In the digital environment of the school, forms of teaching are interesting. The term e-learning can be understood in two ways. Most often, e-learning is understood as an electronic form of distance education. However, e-learning can be broadly understood as electronic learning, which means all that a student can learn through computer, or any other electronic way [9].

Blended learning is a combined teaching - a combination of a standard teaching (attendance, presentation, face-to-face form) with e-learning. This term arose only recently, but our pedagogues have long used a combination of classical forms of teaching with electronic support (for example e-materials are placed on their own or school websites, or are placed on paid portals).

Unlike traditional approaches to education, e-learning is not just one approach that works for everybody. In addition to a wide range of learning styles, which make up the target group, learners most often seek information informally, in a conventional manner. In order for schools to fulfil the needs of formal and informal education, they need different types of educational strategies. These strategies will bring rich possibilities of educational resources to students, in a manner which will be most convenient in a given time, while the content will reflect objectives of the individual, as well as the overall objectives of the university. The reasons for the introduction of e-learning are practical. With respect to the possibilities of Internet services and computer programs it is possible to include "unexpected" benefits that classical education cannot offer. Creation of educational texts for e-learning, which must meet the psychological-didactic aspects are crucial to the active involvement of students in the educational process.

E-learning brings information development into universities and supports their progress. E-learning is simply education of the future. 
Expository - problem method does not only acquaint students with found solutions to certain scientific-cognitive or practical problems and with the method of their applications, but it also shows the logic behind the solution of these problems.

The structure of expository-problem method may be summarized in following stages:

1. Demarcation of problem.

2. Solution process and its logic.

3. Solution process, possible and real difficulties and contradictions.

4. Solution and rationale of its correctness.

5. Clarification of the importance of solutions for the further development of thought or spheres of activity.

In expository - problem method, students follow the logic of pedagogue's interpretation, and control the persuasiveness of his practice and his reasoning in their thoughts. In case of errors in interpretation, doubts and questions arise. The more experience you acquire from creative activity, the more questions and doubts arise.

Students discover not only the final results of the research and the stage of development, but also the relationship between the stages, the paths of progress from one stage to another, typical deviations and obstacles arising in form of new problems. This way, students acquire individual stages of solution of complex problems.

Specificity of expository-problem method consists in the fact that the student does not only perceives, realizes and stores the information but also follows the logic of argumentation, thinking pedagogy, or the means that represent it (information technology, books, etc.). Students learn to think, watch the cogency of the arguments, retrieve them, learn how to be learned, and what is the basis for the development of creativity.

The research method serves for complete acquisition of experience from creative activity. Pedagogue identifies a problem, but solution rests on the student. This method is very well applied in the conception of project teaching where student's activity by its nature approximates activity of the planner, designer, technologist, and economist. Its essence is the submission of a certain task with more comprehensive nature, which should be resolved by students. After introducing the project task (problematic task), and clarification of the problem, solving by students follows. Problems that are addressed in the project teaching are complex; they do not need to be based solely on the content of subject matter, but especially from life. Their solution requires knowledge of several sciences (teaching subjects) the problems are being solved by groups of students (in collaborative learning) out of self-interest. Projects may be proposed by the students themselves, by pedagogues, other entity, or by pedagogues and students together [8].

\section{Conclusion}

The current trend of the onset of digital technology in the lives of students as well as schools inevitably raises questions of their effective use. Experience shows that the educational research as well as in the area of theory of teaching must move in this direction. It is necessary to create quality e-materials and e-tests for utilization in the teaching process. Universities preparing future teachers of science subjects should deal with these questions more intensely in the near future. We believe that by qualified usage of innovative methods of teaching in the digital school, the decreasing trend of popularity of science subjects at schools will stop and perhaps turns around. Possibilities of increasing the effectiveness of security education in conditions of universities are therefore really wide, but it is important to choose the most appropriate in the circumstances given. The need for innovation, security education is also reflected on the theme concept of protection of the population by 2020 , with a view to 2030 in the Czech Republic when one of the strategic points of is the targeted support of science and research, development, innovation, stressing the exploitation of the results achieved in the application sphere within the system education and training of professionals. [10].

\section{References}

[1] LOSONCZI, P., MESAROS, M.: Asymmetry of Understanding Access to the Information Protection (in Slovak), Kosicka bezpecnostna revue, vol. 2, No. 1, University of Security Management : Kosice, 2012, pp. 28-30, ISSN 1338-4880.

[2] KOVACOVA, L., KLIMO, V.: Fundamentals of Security Education in the Process of Globalization, Odes 'kyi Politechnichnyi Universytet Pratsi, No. 2 (41), 2013, Odesa, pp. 217-222, ISSN 2076-2429.

[3] LOSONCZI, P.: Information Security in Primary Schools (in Slovak), Kosicka bezpecnostna revue, vol. 4, No. 2, University of Security Management : Kosice, 2014, p. 77-82, ISSN 1338-4880.

[4] KOVACOVA, L.: Safety Education from the Perspective of University Pedagogy (in Slovak), 3. Intern. conference, University of Security Management : Kosice, 2010, ISBN 978-80-89282-44-9. 
[5] KOVACOVA, L.: Effective and Innovative Trends of Education Security Personnel in Conditions of Universities (in Slovak), Kosicka bezpecnostna revue, vol. 3, No. 1, 2013, University of Security Management : Kosice, pp. 67-72. ISSN 1338-4880.

[6] PETLAK, E.: Options to Streamline the Educational Process (in Slovak), Technologia vzdelavania tretieho tisicrocia: Zborník z vedeckej konferencie, jun 1995, Nitra, 142 p., ISBN 80-967339-1-5.

[7] TUREK, I.: Increasing the Effectiveness of Teaching (in Slovak), Bratislava : Metodicke centrum, 1997, ISBN 80-88796-49-0.

[8] BLASKO, M.: The Quality in the System of Modern Teaching - $1^{\text {st }}$ ed. (in Slovak), Department of Engineering Education : TUKE, 2013, 402 p., ISBN 978-80-553-1281-1.

[9] KORENOVA, I.: Didactic Aspects of Digital Learning School Mathematics (in Slovak), Proc. of VI conference Uziti pocitacu ve vyuce matematky, December 2013, Ceske Budejovice : Jihoceska unverzita, ISBN 978-80-7394-448-3.

[10] KAVAN, S.: New Concept of Protection of the Population in the Czech Republic (in Czech). Zbornik vedeckych prac Manazerstvo bezpecnosti, University of Security Management : Kosice, 2013, 198 p., ISBN 978-80-89282-92-0. 